\title{
Questes
}

vestes Revue pluridisciplinaire d'études médiévales

\section{L'Erreur, l'échec, la faute : éléments bibliographiques}

\section{Florian Besson et Catherine Kikuchi}

\section{(2) OpenEdition \\ 1 Journals}

\section{Édition électronique}

URL : http://journals.openedition.org/questes/4226

DOI : 10.4000/questes.4226

ISSN : 2109-9472

Éditeur

Les Amis de Questes

\section{Édition imprimée}

Date de publication : 30 octobre 2015

Pagination : 145-148

ISSN : 2102-7188

\section{Référence électronique}

Florian Besson et Catherine Kikuchi, « L'Erreur, l'échec, la faute : éléments bibliographiques », Questes [En ligne], 30 | 2015, mis en ligne le 22 novembre 2015, consulté le 15 septembre 2020. URL : http:// journals.openedition.org/questes/4226 


\section{Éléments de bibliographie}

\section{Études générales}

Copie, originalité, authenticité. Questes, dir. Jean-Baptiste CAMPS, Magali CHEYNET et Vincent LE QUENTREC, n ${ }^{\circ}$ 29, mars 2015.

HuIzINGA, Johann, L'Automne du Moyen Âge [1909], trad. Julia BASTIN, Paris, Payot, 2002.

Mattei, Jean-François, Le Sens de la démesure. Hubris et Diké, Paris, Cabris, Éditions Sulliver, coll. « Archéologie de la modernité », 2009.

MONSACRE, Hélène, Les Larmes d'Achille. Le héros, la femme et la souffrance dans la poésie d'Homère [1984], Paris, Éditions du Félin, coll. «Félin poche », 2010.

Précarité, instabilité, fragilité au Moyen Âge, dir. Diane CHAmboduc, Aurélie Houdebert, Cécile TROADEC, actes des Journées d'études de Questes, 14-15 juin 2013, actes à paraître aux PUPS.

ScHAUB, Jean-Frédéric, «Nous, les Barbares. Expansion européenne et découverte de la fragilité intérieure », dans L'Histoire $d u$ monde au $X V^{e}$ siècle, dir. Patrick BOUCHERON, Paris, Fayard, 2009, p. 814-829.

\section{Une lecture pratique et technique}

AGENO, Franca Brambilla, «Gli errori uditivi nella trasmissione dei testi letterari », Italia medievale e umanistica, t. 29, 1986, p. 89-105.

AnsAnI, Michele, "Caritatis negocia» e fabbriche di falsi. Strategie, imposture, dispute documentari a Pavia fra XI e XII secolo, Istituto storico italiano per il Medio Evo, Rome, 2011.

CERQuiglini, Bernard, Le Roman de l'orthographe. Au paradis des mots, avant la faute 1150-1694, Paris, Hatier, coll. «Brèves littératures », 1996.

DeBray, Régis, Christophe Colomb, le visiteur de l'aube, Paris, La Différence, coll. « Les Voies du sud », 1991.

ECO, Umberto, La Guerre du faux, Paris, Grasset, 1985.

HAVET, Louis, Manuel de critique verbale appliquée aux textes latins, Paris, Hachette, 1911. 
Prager, Frank et SCAglia, Gustina, Brunelleschi. Studies of his Technology and Inventions [1970], Dover, Courier Dover Publications, 2012.

RÖMER, Thomas, Les Cornes de Moïse. Faire entrer la Bible dans l'histoire, Paris, Fayard, coll. «Leçons inaugurales du Collège de France », 2009.

VEZIN, Jean, Les Scriptoria d'Angers au XI siècle, Paris, Champion, coll. «Bibliothèque de l'École des hautes études. 4e section. Sciences historiques et philologiques », 1974.

WeILl-Parot, Nicolas, Points aveugles de la nature. La rationalité scientifique face à l'occulte, à l'attraction magnétique et à l'horreur du vide (XIII ${ }^{e}-X V^{e}$ siècle), Les Belles Lettres, coll. « Histoire », Paris, 2013.

\section{Une lecture politique et juridique}

BeAulande, Véronique, Le Malheur d'être exclu? Excommunication, réconciliation et société à la fin du Moyen Âge, Paris, Publications de la Sorbonne, coll. « Histoire ancienne et médiévale », 2006.

BLOCH, Marc, «Les Formes de la rupture de l'hommage dans l'ancien droit féodal », Revue historique de droit français et étranger, $\mathrm{n}^{\circ} 36,1912$, p. 141-177.

Chiffoleau, Jacques, Les Justices du Pape. Délinquance et criminalité dans la région d'Avignon au XIV siècle, Paris, Publications de la Sorbonne, coll. « Histoire ancienne et médiévale », 1984.

L'Erreur judiciaire. De Jeanne d'Arc à Roland Agret, dir. Benoît GARNOT, Paris, Éditions Imago, 2004.

La Faute, la répression et le pardon. Actes du $107^{e}$ Congrès national des sociétés savantes, Brest, 1982, section de philologie et d'histoire jusqu'à 1610, Paris, CTHS, 1984.

Gauvard, Claude, «De Grace especial ». Crime, État et Société en France $\grave{a}$ la fin du Moyen Âge, Paris, Publications de la Sorbonne, coll. «Histoire ancienne et médiévale», 1991. (notes de lecture: LETT, Didier, Médiévales, vol. 12, $\mathrm{n}^{\circ}$ 25, 1993, p. 150-153).

-, Violence et ordre public au Moyen Âge, Paris, Picard, coll. «Les médiévistes français », 2005.

GONTHIER, Nicole, Le Châtiment du crime au Moyen Âge, Rennes, PUR, coll. « Histoire », 1998.

LEMESLE, Bruno, Conflits et justice au Moyen Âge. Normes, loi et résolution des conflits en Anjou aux XI et XII siècles, Paris, PUF, coll. « Le Noeud gordien », 2008. 
Les Rites de la justice: gestes et rituels judiciaires au Moyen Âge, dir. Claude GauvarD, Paris, Le Léopard d'or, coll. « Cahiers du Léopard d'or », 2000.

TOUREILLE, Valérie, Vol et brigandage au Moyen Âge, Paris, PUF, coll. « Le Noeud gordien », 2006.

-, Crime et châtiment au Moyen Âge, $V^{e}-X V^{e}$ siècle, Paris, Seuil, coll. «L'Univers historique », 2013.

La Trahison au Moyen Âge, dir. Maïté BILlore et Myriam SoRIA, Rennes, PUR, coll. « Histoire », 2009.

\section{Une lecture théologique et morale}

Boureau, Alain, Satan hérétique. Naissance de la démonologie dans l'Occident médiéval, 1280-1330, Paris, Odile Jacob, 2004.

-, «L'individu, sujet de la vérité et suppôt de l'erreur. Connaissance et dissidence dans le monde scolastique (vers 1270-vers 1330)», dans L'Individu au Moyen Âge, dir. Dominique IognA-PrAT et Brigitte BedosREZAK, Aubier, Paris, 2005, p. 289-306.

-, «La Passion et la faute. Nouvelles approches des émotions médiévales », Critique, $\mathrm{n}^{\circ} 716-717,2007 / 1$, p. 36-46.

De la faute et du salut dans l'histoire des monothéismes. Actes de colloques en histoire comparée, dir. Dominique AVRON et Karam RIZK, Paris, Karthala, coll. « Signes des temps », 2010.

Delumeau, Jean, Le Péché et la peur. La culpabilisation en Occident, XIII ${ }^{e}$ XVIII siècle, Paris, Fayard, 1983.

Node-Langlois, Michel, Le Vocabulaire de saint Thomas d'Aquin, Paris, Éllipses, coll. « Vocabulaire de... », 2009.

Schatz, Klaus, La Primauté du pape. Son histoire, des origines à nos jours, Paris, Cerf, coll. «Librairie européenne des idées », 1992.

Vigarello Georges, Les métamorphoses du gras. Histoire de l'obésité, Paris, Editions du Seuil, 2010, chapitre III « l'horizon de la faute».

Vogel, Cyrille, Le Pécheur et la pénitence dans l'Église ancienne, Paris, Cerf, coll. «Chrétiens de tous les temps », 1982. 


\section{Une lecture historique et romanesque}

Alexandre le Grand, figure de l'incomplétude, dir. François DE POLIGNAC, Rome, École Française de Rome, 2000.

Crime et châtiments dans la chanson de geste, dir. Bernard RIBEMONT, Bruxelles, Klincksieck, 2008.

Crouzet-PAVAn, Élisabeth, Le Mystère des Rois de Jérusalem, 1099-1187, Paris, Albin Michel, coll. « Bibliothèque histoire », 2013.

Dauphant, Clothilde, "Qu'est devenu David et Salemon ? Les Hommes illustres dans la poésie d'Eustache Deschamps », Questes. Les Hommes illustres, dir. Marion CHAIGNE et Anne SALAMON, $\mathrm{n}^{\circ}$ 17, décembre 2009, p. $99-119$.

La Faute dans l'épopée médiévale. Ambiguïté du jugement, dir. Bernard RIBEMONT, Rennes, PUR, coll. « Histoire », 2012.

LE GofF, Jacques, Héros et merveilles du Moyen Age, Paris, Seuil, 2005.

LEVRON, Pierre, "Quand l'Ours devient faible. Arthur et ses défaillances », Questes. Figures royales à l'ombre du mythe, dir. Natalia BERCEABoCsKAI et Amandine Mussou, $n^{\circ} 13$, janvier 2008, p. 8-23.

MARTINEZ-Gros, Gabriel, L'Idéologie omeyyade. La construction de la légitimité du califat de Cordoue, $X^{e}-X I^{e}$ siècles, Madrid, Casa de Velázquez, coll. «Bibliothèque de la Casa de Velázquez », 1992.

-, Identité andalouse, Arles, Sindbad-Actes Sud, coll. «La bibliothèque arabe. Hommes et sociétés », 1997.

Morris, Ivan, La Noblesse de l'échec. Héros tragiques de l'histoire du Japon, Paris, Gallimard, coll. «La Suite des temps », 1980.

Réécriture et falsification dans l'Espagne médiévale, dir. Marta LACOMBA et Carlos Heusch, ENS éd., Lyon, 2006.

Roman, Agathe, L'Erreur et la faute dans l'Histoire de la guerre du Péloponnèse de Thucydide, Louvain/Namur/Paris, Peeters/Société des études classiques, 2012. 